\title{
Antibiotic Susceptible Pattern of Pseudomonas aeruginosa Isolated from Clinical Specimens in a tertiary care centre Hospital Narayana Medical College and Hospital - Nellore, AP, India
}

\author{
N. Premanadham*, P. Srinivasulu Reddy, K. Jithendra, B. Siva Prasad Reddy \\ and P.Vasundhara
}

Microbiology Department Narayana Medical College, Nellore, India

*Corresponding author

\begin{abstract}
A B S T R A C T
Keywords

Pseudomonas aeruginosa, Antibiotic Susceptible Pattern

\section{Article Info}

Accepted:

14 September 2016

Available Online:

10 October 2016

A total of 215 greenish, pigmented consecutive non-duplicate Pseudomonas aeruginosa isolates from clinical specimens were examined. The age of the patients was 2-75 years, comprised of 164 (76. 68\%) males and 51 (23. 72\%) females. High prevalence of pseudomonal infections occurred more in above 60years (33. $95 \%)$, followed by 40-49(18\%) and 50-59(17. 67\%) 20-29(12. 09\%);30-39(10. $23 \%) 10-19(06.51 \%)$ least in less than $10 y e a r s(0.93 \%)$. Majority of the isolates were recovered from wounds specimens, 54(25. 12\%). and urine 54(25. 12\&) next f0llows sputom34 (15. 81\%), endotrachial tube 32 (14. 88\%), pus 17(07.91\%) cathetertip14 (06. 51\%), body fluids 10(04. 65\%) Overall antibiotic susceptibility pattern showed that highest sensitivity of piperacilliin plus tazobactam $176(81.86 \%)$, followed by dorepenen $172(80 \%)$ imepenem, 170(79. 07\%) polymixin-B, 52 [70. $70 \%$ ]. Amikacin 140(68. 12\%), ciprofloxacin 135 (62.75\%. Highest resistance seen in amoxicillin 203(94. 42\%) followed by cefexime $170(79.07 \%)$, cotrimoxazole130 (60. 47\%) cefipime 125 (58. 14\%) Majority of the isolates exhibited multidrug resistance pattern. In conclusion, the multidrug resistance pattern of $P$. aeruginosa isolates observed in this study posed a dire clinical consequence, especially in patients management with pseudomonal infections and infections control approach in hospital environment due to rapid dissemination of the strains.
\end{abstract}

\section{Introduction}

Pseudomonas aeruginosa, is a motile gramnegative rods that belongs to the family Pseudomonadaceae. It is a leading cause of nosocomial infections, especially among critically ill admitted in intensive care unit, immune-compromised patients. It has been implicated in diverse nosoicomial infection likes nosocomial pneurnonis, urinary tract infection, surgical site infection, severe burns and infections of patient undergoing either chemotherapy for neoplastic disease or those on antibiotics therapy (Gilligan, 1995; Baron et al., 1995) $P$. aeruginosa is widely distributed in narture, but has higher prevalence in hospital environment, as the wards encourages bacterial growth 
(Greenwood et al., 1998). The characteristic features of $P$. aeruginosa isolates that allows the persistence in hospital is the ability to acquires resistance to variety of antibiotics, withstands physical conditions like temperature, high concentration of salts and antiseptics.

Epidemiologically, it is ranked as the fourth cause of nosocomial infections that accounts for $10 \%$ of all nosocomial infection in the United States. Overall prevalence in US hospital was approximately 4 per 1000 discharge and leading cause of high morbidity and mortality (Rah et al., 1943). In studies conducted in narayana medical college \&general hospital, it is one of the leading gram-negative bacteria isolated from clinical specimens in hospital-based studies( $\mathrm{r}$ $P$. aeruginosa isolates are naturally resistant to large number of antibiotics that can be acquired during treatment (Zonfiglio et al., 1995) of as a result of treatment failure (Rah et al., 1995). Consequential effect of high resistance pattern is responsible for high mortality rate associated pseudomonas infections (Samporn et al., 2004).

Antibiotic resistance pattern of $P$. aeruginosa isolates varied with geographical location and hospitals environments. Therefore, chemotherapeutic approach of pseudomonal infection would depend on peculiarity of the isolates susceptibility pattern in order to safeguard against treatment. In this context, this study examined the antibiotic resistance of $P$. aeruginosa isolates from clinical specimen in a tertiary hospital.

\section{Materials and Methods}

The study was conducted in the Narayana General Hospital and college Microbiology Laboratory. Study was conducted between June 2015 to July 2016. Narayana General Hospital is a teaching hospital having 1000 bed strength. It is a major referral centre for many hospitals in and around Nellore. It has super specialties cardiology, nephrology. urology, surgical gastroenterology, cardiothoracic surgery with sub-specialties in Internal Medicine, Surgery, Pediatrics, Obstetrics and Gynecology and Pathology. Approximately 20, 000 clinical specimens are received in medical microbiology laboratory per year. Over the study period, 215 greenish pigmented, non-duplicate consecutive $P$. aeruginosa isolated from the clinical specimens were identified by standard bacteriological methods (colonial morphology, citrate, and oxidase etc). The isolates were recovered from wound, urine, pus, endotrachial tube, catheter tips and body fluids. Demographic information on the isolates includes the age of the patient, sex, type of clinical specimens and wards. . Antibiotic susceptibility testing was determined by disc diffusion method using Mueller-Hinton agar plates.

Bacterial suspension was prepared in Andrase peptones water to give concentration an equivalent of 0 . $5 \mathrm{McFarlane}$ standards. The bacterial suspension were inoculated on the MuellerHinton agar plate by swabbing to give a smooth lawn, and antibiotic discs were placed on it, incubated at $37^{\circ} \mathrm{C}$ overnight.

The following antibiotic discs were tested, amoxicillin (30ug) cefexime (30ug), ceftazidine (30ug), cefepime (30ug) co trimaxazole (30ug), ciprofloxacin (l ug), ofloxacin (1ug), gentamycin (I ug), amikacin (30ug), polymixin-B (10ug), tegycycline (10ug) cefeperazone plus salbactem (75/30), peperacillin plus tazobactem (100/10 ug) imepenem (10ug), dorepenem (10ug). The zone of inhibition diameter was measured using calibrated ruler and interpreted as susceptible, intermediate or resistant in accordance to CSLT guidelines. Multidrug resistance is defined as isolates resistance to 
more than three classes of drugs.

\section{Results and Discussion}

Over 12 month study period, $P$. aeruginosa isolates accounted for 215. The age of the patient was range 2-75 years. gender distribution showed that male patients were 164 (76. 26\%) and 51(26. 72\%) females. High frequency of pseudomonal infection was more above the age-60 years $(33.9 \%)$ followed by40-49 (18. 60\%), 50-59 (17. 67\%) 20-29- (12.09\%) 30-39 (10. 23\%1019(6. 91\%))a nd least in less than 10years $((0.93 \%) \%)$ (Table I).

Significant proportion of isolates were recovered from wounds specimen 54(25, $12 \%)$ and urine $54(25.12 \%)$ followed by sputum 34(15. 81) ET32 (14. 38\%), pus 17 (7. $9 \%)$ catheter tips $14(6.51 . \%)$ urine) body fluids $10(4.65 \%)$ high in wound and urine least in body fluids (Table II).

The antibiotic susceptibility pattern of $P$. aeruginosa isolates as presented in Tables III, showed that the isolates were highly susceptible pipercillin plus tazobactem
176(81. 86\%), doperenem172(80\%), imepenem 170(79. 07\%) polymixin-B152 (70. $70 \%)$ amikacin $140 \quad(65 . \quad 12 \%)$ ciprofloxacin 135 (62.75\%), cotrimaxazole $130(60.47 \%)$ and moderately to cefepime $125(58 \%)$ ticarcillin $122 \quad(57,21 \%)$ ceftazide=ine $109(50.70 \%)$ and least to ofloxacin100(46. 5i\%). High level of resistance was observed withamoxicillin 203(94\%), cefixime 170 (79. 07\%). Majority of the isolates that exhibited multidrug resistant pattern.

Pseudomonas aeruginosa is ranked second among gram-negative bacteria isolated in hospital environmental, and leading cause of nosocomial infections responsible for morbidity and mortality rate. High prevalence of pseudomonal infections is common among critically ill patients on admission on intensive care unit and those with underlying clinical conditions (Raja et al., 2007) epidemiological data of bacterial pathogens as in this study might be difficult as there are other variables that influences the outcome of results such as, clinical specimens received for examination, studied population, type of hospitals and geographical locations.

Table. 1

\begin{tabular}{|c|c|c|c|c|c|c|}
\hline Age & & & & male & & \\
\hline$<10$ & 2 & $(0.93)$ & 0 & $(0.00)$ & 2 & $(0.93)$ \\
\hline 10-19 & 8 & $(3.72)$ & 6 & $(2.79)$ & 14 & $(6.51)$ \\
\hline 20-39 & 20 & $(9.3)$ & 6 & $(2.79)$ & 26 & (12.09) \\
\hline $30-49$ & 15 & (6.98) & 7 & $(3.26)$ & 22 & $(10.23)$ \\
\hline $40-49$ & 29 & $(1.39)$ & 11 & $(5.12)$ & 40 & (18.60) \\
\hline $50-59$ & 28 & (13.02) & 10 & $(4.65)$ & 38 & (17.68) \\
\hline Above 60 & 62 & $(28.84)$ & 11 & $(5.12)$ & 73 & $(33.95)$ \\
\hline Total & 164 & (76. 28) & 51 & $(23.72)$ & 215 & $(100)$ \\
\hline
\end{tabular}

Table. 2 Distribution of isolates in varies clinical samples 


Clinical specimen
Body fluids
Endotrachial tube
Pus
Sputum
Wounds
Catheter tip
Urine
$\quad$ Total

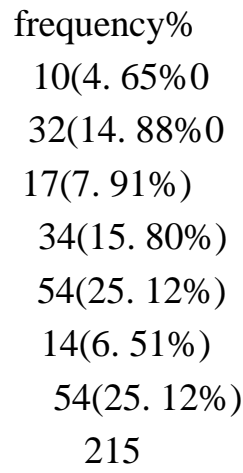

Table. 3

Antibiotics

Amoxicillin

CEFIXIME

CEFTAZIDIME

CEFIPIME

CO-TRIMOXAZOLE

47)

CIPROFLOXACIN

OFLOXACIN

AMIKACIN

TEGICYCLINE

POLYMYXIN-B

CEFPERAZONE+SULBACTAM

TICARCILINUTCLASAR

PIPERACILLIN+TAZOBACTAM

IMIPENEM

DOREPENEM sensitivity

$12(5.58)$

$45(20.93)$

$106(49.30)$

$90(41.86)$

85 ( 39.53$)$

$135(62.79)$

$115(53.49)$

$140(65.12)$

$119(55.35)$

152(70.70)

123(57.21)

92(42.79)

$176(81.86)$

170(79.07)

172(80.00) resistance

203 (94. 42)

$170(79.07)$

109 (50.70)

$125(58.14)$

130( 60 .

$80(37.21)$

100(46. 51)

73(88)

96(44.65)

63(29. 30)

92(42.79)

122(57.21)

39(18. 14)

45(20. 93)

43(20.00)
Prevalence of $P$. aeruginosa isolates varied with clinical conditions and specimens. In the European Prevalence of Infection in Intensive Care (EPIC), $P$. aeruginosa was predominant gram-negative bacteria isolated from bronchopulmonary infections and accounts for $17 \%$ of health care-associated pneumonia and late onset ventilate associated pneumonia and accounts for significant cases of cystic fibriosis. The distribution of isolates differs with studies and clincal specimens, In Zaria, Olayinka et al., 2004 reported 51. $1 \%$ in urine, $41.3 \%$ in wound and $1.1 \%$ in sputum, while $4.6 \%$ in urine in Jos. In Ile-Ife, southwestern Nigeria, prevalence of $11.1 \%$ in open musculoskeletal injuries', and in Ibadan, isolate rate of $16.8 \%$ with $41.9 \%$ and 39.35 from ear and wound swab respectively (Ogbolu et al., 2008).

However, the possibility of $P$. aeruginosa contaminators of wounds and catheter tips cannot be ruled out. This is possible in hospital environment where strict hand washing procedure is not strictly adhered to 
and unhygienic procedure especially in wound dressing and insertion of indwelling catheter may be a contributory factor. Majority of isolates were recovered from patient on admission, this observation affirmed the significant role of this organism in nosocomial infection, similarly was the pattern in wounds and catheter tip specimens.

The unique feature of $P$. aeruginosa isolates is the resistance to variety of antibiotics, primarily attributed to low permeability of the cell wall, production of inducible cephalosporinase, active efflux and poor affinity for the target (DNA gyrase) (Lim et al., 2009).

In this study highest sensitivity was seen in combination drugs like piperacllin and tazobactem (81. 86\%). sensitive to carbapenems like domperenem (80. 00\%) and imepenem (79.07\%) was comparatively high. similar studies like Aljesser and Elkhizzi (2004) sensitivity of imepenem(90. $1 \%)$ and piperacillin and tazobactem $(90$. 6\%). raja and singh (2007) showed sensitivity to imepenem (90. 1\%), piperacillin and tazobactem (90.6\%).

Sensitivity to cefepime and ceftazidine ranges from $40=50 \%$ is same as study conducted by Garba et al.

Highest resistance was seen to amoxicilline (97. 4\%)similar to Garba et al., resistance to coprofloxacin and oflaxacin ranges from50$60 \%$ Most disturbing pattern observed in this study was the multidrug resistance exhibited by most of the isolates (no pan drug resistance). Although, similar pattern had been reported in studied conducted in Zaria", in Jamacia29, in Italy", Saudi Arabia;' and Brazir.

In conclusion, the multidrug resistance by $P$. aeruginosa isolated in this study posed direct clinical consequence in term of patient management and infection control approach in hospital environment. and also more restricted and rational use of these drugs is necessary.

\section{References}

Akinyola, A.L., Ako-Nai, A.K. 2005. Microbial isolates in early swabs of musculoskeletal injuries. West African J. Med., 24(3): 273-278.

Baron, R.R., E.J., Pfaler, M.A., Tenover, F.C., Yolken, R.H. 1995. Manual of Clin. Microbiol., Washington DC, American Society of Microbiology, pp: 509-519.

Cheesbrough, M. District Laboratory Practice in Tropical2(r))51(r)1tries (2nd ed). Cambridge, Cambridge University Press,

Fadeyi, A., Akanbi, A.A., Ndubisi, C., Onile, B.A. 2005. Antibiotic disc sensitivity pattern of Pseudomonas aeruginosa isolates obtained from clinical specimens in Ilorin, Nigeria. Nigerian J. Med. Sci., 34(3): 303-306.

Gilligan, P.H. Pseudomonas and Burkholderia. In Murray

Govan, J.R.W. Pseudomonads and nonfermenters. In:

Greenwood, D., Slack, R.C.B., Peutherer, J.F. (eds.). 1998. Medical Microbiology. Edinburgh, Churchill Livingstone 1998; 284-289. . 3. Hugbo PG, Olurinola PF. Resistance of Pseudomonas aeruginosa to antimicrobial agents: Implications in medicine and pharmacy. Nigerian $J$. Pharma. Sci., 4: 1-10.

Ikem, I.C., Oginni, L.M., Adegbehinde. 2004. The bacteriology of open fractures in Ile-Ife, Nigeria. Nigerian J. Med., 13(4): 359-365.

Kehinde, A.O., Ademola, S.A., Okesola, A.O. 2004. Pattern of bacterial 
pathogens in burn wound infections in Ibadan, Nigeria. Annals of Burns, Fire and Disasters.

Lim, K.T., Yasin, R.Y., Yeo, C.C., et al. 2009. antimicrobial suscepatbility proile of $P$. aeruginosa isolates in Malacia. J. Microbiol. Infect. Dis, 42: 197-209.

Oduyebo, O., Ogunsola, F.T., Odugbemi, T. 1997. Prevalence of multi-resistant strains of $P$. aeruginosa isolated at the Lagos University Teaching Hospital from 1994 -1996. Nigerian Quarterly J. Med., 7: 373-376.

Ogbolu, D.O., Ogunledun, A., Adebiyi, D.E., Daini, O.A., Terry, A.O. 2008. Antibioticsensitivity pattern $\mathrm{O} P$ aerugenosa to awailable Anti psuedomonal drusin Ibadan, Nigeria, African J. Med. Sci., 37(3): 339-344.

Olayinka, A.T., Onile, B.A., Olayinka, B.O. 2004. Prevalence of multi-drug resistant (MDR) Pseudomonas aeruginosa isolates in surgical units in Ahmadu Bello University Teaching Hospital, Zaria, Nigeria: An indication for effective control measures. Annals of African Med., 3(1): 13-16.

Olorunfemi, P.O., Onaolapo, J.A. 1988.
Comparative activities of some commonly used antibacterial agents on S. aureus, E. coli and $P$. aeruginosa. Nigerian J. Pharma. Sci., 4: 53-57.

Rah, P., S. Cunha, A.B., Dua, P. et al. 2008. Pseudomonas aeruginosa infections, Available from: http://www. emedicine. com/med/topic 1943. html

Raja, N.S., Sing, N.N. 2007. Antimicrbial susceptible pattern clinical islates $P$. aerugenosa in terciary care hospital. $J$. Microbiol. Immunol. Infect., 40: 45-49.

Samporn, S., Chuntima, T., Thitiya, Y., Chertask, D. 2004. Prevalence and antimicrobial susceptibility of Pseudomonas aeruginosa mucoid and non-mucoid type. Southeast Asia J. Trop. Med. Pub. Health , 35: 1893894.

Zlrdem, B. 1999. Pseudomonas. 1n: Ustacelebi S (ed) Basic LClinical Microbiology. Ankara, Gunes Publication, pp: 551-558.

Zonfiglio, G., Laksai, Y., Franchino, L. et al. 1998. Mechanism of actam resistance amongst Pseudomonas aeruginosaisolated in an Italian survey. J. Antimicrob. Chemother., 42: 697702.

\section{How to cite this article:}

Premanadham, N., K. Srinivasula Reddi, K. Jitendra and Siva Prasa Reddi. 2016. Antibiotic Susceptible Pattern of Pseudomonas aeruginosa Isolated from Clinical Specimens in a Tertian Hospital Narayana Medical College and Hospital - Nellore, AP, India. Int.J.Curr.Microbiol.App.Sci. 5(10): 324-329. doi: http://dx.doi.org/10.20546/ijcmas.2016.510.036 